\title{
TU/e EN⿴HONE

\section{Digital image correlation for analyzing portable electronic products during drop impact tests}

\section{Citation for published version (APA):}

Scheijgrond, P. L. W., Shi, D. X. Q., Driel, van, W. D., Zhang, G. Q., \& Nijmeijer, H. (2005). Digital image correlation for analyzing portable electronic products during drop impact tests. In Proceedings of the 6th International Conference on Electronics Packaging Technology 30 august - 2 september 2005, Shenzhen, China (pp. 1-6) https://doi.org/10.1109//CEPT.2005.1564683

DOI:

10.1109/ICEPT.2005.1564683

Document status and date:

Published: 01/01/2005

\section{Document Version:}

Accepted manuscript including changes made at the peer-review stage

\section{Please check the document version of this publication:}

- A submitted manuscript is the version of the article upon submission and before peer-review. There can be important differences between the submitted version and the official published version of record. People interested in the research are advised to contact the author for the final version of the publication, or visit the $\mathrm{DOI}$ to the publisher's website.

- The final author version and the galley proof are versions of the publication after peer review.

- The final published version features the final layout of the paper including the volume, issue and page numbers.

Link to publication

\section{General rights}

Copyright and moral rights for the publications made accessible in the public portal are retained by the authors and/or other copyright owners and it is a condition of accessing publications that users recognise and abide by the legal requirements associated with these rights.

- Users may download and print one copy of any publication from the public portal for the purpose of private study or research.

- You may not further distribute the material or use it for any profit-making activity or commercial gain

- You may freely distribute the URL identifying the publication in the public portal.

If the publication is distributed under the terms of Article 25fa of the Dutch Copyright Act, indicated by the "Taverne" license above, please follow below link for the End User Agreement:

www.tue.nl/taverne

Take down policy

If you believe that this document breaches copyright please contact us at:

openaccess@tue.nl

providing details and we will investigate your claim. 


\title{
Digital Image Correlation for Analyzing Portable Electronic Products during Drop
}

\section{Impact Tests}

\author{
P.L.W. Scheijgrond ${ }^{1,2}$, D.X.Q. Shi ${ }^{2}$, W.D. van Driel $^{3}$, G.Q. Zhang ${ }^{3}$, H. Nijmeijer ${ }^{1}$ \\ ${ }^{1}$ Department of Mechanical Engineering, Eindhoven University of Technology, Eindhoven, The Netherlands \\ ${ }^{2}$ Philips Mobile Display Systems, Shanghai, China \\ ${ }^{3}$ Philips Semiconductors, Nijmegen, The Netherlands \\ Email: P.L.W.Scheijgrond@student.tue.nl
}

\begin{abstract}
In this paper the feasibility to analyze a guided free fall drop of portable electronic products by optical inspection using digital image correlation is studied. This technology can examine the product on every arbitrary place on its surface and allows the product to make guided free fall drops. For this study, a mobile phone is dropped on a pavement stone under different orientations and heights. The phone is prepared with a speckle and the impact is recorded by using a high-speed camera. A custom made program based on digital image correlation is used to calculate the displacement fields during the impact. Out of these results deformations, strains, G-levels, velocities, energy losses, rotations and bending are calculated. Both local and global phenomena are measured and different impact orientations and heights are examined. The results provide new insights in drop test performance.
\end{abstract}

\section{Introduction}

Nowadays a growing numbers of drop tests are being conducted, but test methods and results vary a lot. Tests can be broken down into two catagories, namely tests on product level, in which the whole product is dropped, and tests on board level, in which a part of the product is dropped.

The reliability of a product is often tested by tumble tests, in which the product is dropped several times without measuring the drop. These tests provide statistical information about the amount of drops a device can withstand.

On board level different guided drop tests are performed $[1,2]$. In these tests information about the accelerations and strains is acquired using local measurements. The strain gages are placed on the board and the accelerometers next to the board, according to the JEDEC standard [7]. On product level guided drop tests are conducted with a cellular phone [3]. For this test a high speed camera is used to get an indication of the overall impact behavior and an accelerometer is used to measure the local response during impact.

Impact on PCBs during a guided free fall under different impact orientation is measured on both product level and board level [4], in which big variations of accelerations and strains are measured under different impact orientations. These tests are all limited to measurements of acceleration or strain on small areas on the product.

In materials technology displacements and strains are often studied by using digital image correlation [5, 6]. This technology correlates a pair of digital speckle patterns obtained at two different moments in time and searches for the location of a point within the speckle pattern, with the best match in gray-level distribution of a defined subset, by maximizing the correlation coefficient. The location where the best match is found indicates the displacement of a pixel after the step in time. This technology provides a wide range of measurement sensitivity and resolution for macroand micro-scale displacement measurements and is a noncontact measurement.

This study explores digital image correlation, in combination with a high-speed camera, to inspect the drop impact of a phone during a guided free fall. This non contact technology allows the use of guided free falls, which are more realistic than a guided drop, and it can provide information about the position of every arbitrary point on the surface of the phone. Based on the position of different points on the phone, both global and local movements can be examined, out of which different parameters are obtained, which can in turn be combined to improve the understanding of the impact behavior of a mobile phone. The obtained results provide new insights in phenomena occurring during the impact, which are the basis for:

- $\quad$ evaluation of finite element

- input for finite element simulations

- new design rules

The paper is organized as follows. Section II describes the test set up and the way the tests are conducted. In section III, it is explained how the different parameters are calculated and an estimation of the accuracy of those parameters is given in section IV. The results obtained from 3 different drop tests are described in section $\mathrm{V}$, followed by the conclusions of the study. 


\section{Experimental Set-up}

In this test a commercially available phone is prepared with a random speckle, that provides sharp contrast in gray levels between adjacent pixels. One high speed camera is used, which limits the amount of drop orientations and only movements that stay in one plane are captured. In this test the left side of the phone is examined during horizontal and vertical drops from 1.5 and 2 meter. These drops are well orientated and almost no movements out plane of the left side of the phone take place.

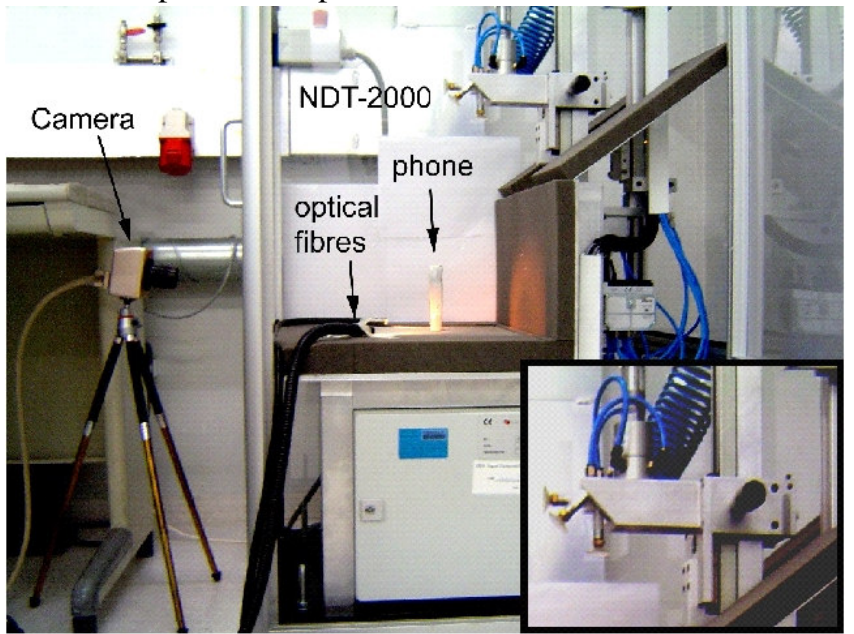

Figure 1: Overview on the test set up

The used drop test facility is the NDT-2000, produced by Herstad+Piper A/S, which is a guided free fall drop test facility that can control different impact orientations, see figure 1. To control the orientation the phone is attached in a certain angle on suction cups, which hold the phone by vacuum, see the enlargement in figure 1. The drop height is 1.5 meter or 2 meter and the phone is guided along a slider till 40 centimeter above the concrete tile, after which the phone is realeased for a free fall. The impact is lighted by two light sources and filmed by a high speed camera, that can work on varying framerates till $32000 \mathrm{fps}$, on which a resolution of 32 x 512 pixels and 256 graylevels is provided. At lower framerates the resolution is higher and goes up to 512 x 512 on $2000 \mathrm{fps}$. Often a framerate of $8000 \mathrm{fps}$ is used, which comes with a resolution of $128 \mathrm{x}$ 512 pixels. The user can choose to film the whole phone or zoom in on a specific part of the phone by placing the camera head further or closer to the cabinet. When a good recording of an impact is made, a ruler is recorded to measure the scale of one pixel, which varies from 238 $\mu \mathrm{m} /$ pixel to $173 \mu \mathrm{m} /$ pixel.

\section{Data Processing}

The principle of the digital image correlation is to compare two digital images made at two different moments in time and search for a match between a subset of pixels, $A_{r}$, in the first image and a subset of pixels, $A_{t}$, in the second image by maximizing the correlation coefficient $C$ $[5,6]$.

$$
C(u, v)=\frac{\sum_{i=1}^{m} \sum_{j=1}^{m}\left[f\left(x_{i}, y_{j}\right)-\bar{f}\right] \cdot\left[g\left(x_{i}^{\prime}, y_{j}^{\prime}\right)-\bar{g}\right]}{\sqrt{\sum_{i=1}^{m} \sum_{j=1}^{m}\left[f\left(x_{i}, y_{j}\right)-\bar{f}\right]^{2}} \cdot \sqrt{\sum_{i=1}^{m} \sum_{j=1}^{m}\left[g\left(x_{i}^{\prime}, y_{j}^{\prime}\right)-\bar{g}\right]^{2}}}
$$

(1)

Here $u$ and $v$ are the displacements of the subset in $\mathrm{x}$ and $\mathrm{y}-$ direction, $f\left(x_{i}, y_{j}\right)$ and $g\left(x_{i}, y_{j}^{\prime}\right)$ are the gray values at points $\left(x_{i}, y_{j}\right)$ and $\left(x_{i}, y_{j}\right)$ on the subsets $\mathrm{A}_{\mathrm{r}}$ and $\mathrm{A}_{\mathrm{t}}$, respectively, and $\bar{f}$ and $\bar{g}$ are the mean graylevels of the subsets $\mathrm{A}_{\mathrm{r}}$ and $A_{t}$. The number of possible positions is limited through defining a search region in which the match is expected to be found. Within this region the correlation coefficient is calculated for every discrete position and the position with the highest correlation coefficient is taken as the new position for this coarse search.

In order to achieve subpixel accuracy, a bicubic spline interpolation is employed on the subset $A_{t}$ to obtain gray level values between the pixels, so the subset $A_{r}$ can be mapped on positions within one pixel accuracy. A fine search is employed to map the subset $A_{r}$ on the positions within subpixel accuracy. A normal fine search examines every possible position within the interpolated area, but that can be speeded up by implementing a line search algorithm $[5,6]$. The position with the subset $A_{t}$ that matches best the subset $A_{r}$ is taken as the new position and the subset $A_{t}$ becomes the new reference subset $A_{r}$ for the next image, so fluctuations in graylevel will be reduced.

The calculated positions of dots have a discrete nature, but real positions vary in a continuous way. Therefore a smoothing algorithm is implemented so continuous grids are achieved. Over time, the positions are smoothed by a butterworth low pass filter, which eliminates the high frequency fluctuations. To further reduce the error some of the calculations use the average of the positions of a group of dots.

The positions in meters can be calculated by multiplying the calculated positions with the recorded scale. The change in position and the framerate determine the velocity and the accelerations.

$$
\begin{aligned}
& v=\left(\operatorname{pos}_{i+1}-\operatorname{pos}_{i}\right) \cdot \text { framerate } \\
& a=\left(v_{i+1}-v_{i}\right) \cdot \text { framerate }
\end{aligned}
$$

The strains are calculated from the displacement, $u$, and position, pos, of two different points, $i$ and $i+1$.

$$
\varepsilon=\frac{u_{i+1}-u_{i}}{p o s_{i+1}-p o s_{i}}
$$

When a grid of points is calculated, a linear line fit can be made through the different rows. The mean slope of those lines gives an indication for the rotation of the phone. The difference between the actual position of a dot and the line fit is used to visualize the bending of the phone. 


\section{Accuracy}

To verify the implemented algorithm a recording of a known movement sequence of a speckle is made with a microscope. The algorithm has calculated the positions of different dots on different integration accuracy levels. At integration levels higher than 4 the error remains the same and most calculations in this study are done with an integration level of 5, which gives an accuracy of 0.03 pixel. The algorithm can detect small rotations, but for big rotations errors appear, which are due to the fact that the subset $A_{t}$ is rotated and the algorithm maps $A_{r}$ in an unrotated way on $A_{t}$. The fluctuations between the calculated positions of the different dots become bigger further in the image sequence, which is due to the update of the subset $A_{r}$ after every step in the sequence.

The graylevels of the recorded speckle are the source for the digital image correlation algorithm. Fluctuations in the gray levels during the drop test reduce the accuracy. Those fluctuations are mainly due to small movements of the phone out of the recorded plane or fluctuations in the light intensity.

A limitation of the algorithm is that subsets can move out of the image before the pixel moves out of image, which limits the movement range of the examined dots.

In this study the normal fine search is used, because the results obtained with fast fine search methods show a lower correlation coefficient than the normal fine search.

The position strongly depends on the accuracy of the digital image correlation algorithm of which it is impossible to give an accuracy budget. Assuming the algorithm performs well the accuracy budget of the position can be calculated:

$\Delta$ pos $=n \cdot \frac{\text { scale }+\Delta \text { scale }}{2^{\text {int }}}$

In which $n$ is the number of the examined image, scale is the pixel scale, $\Delta$ scale is the uncertainty in scale and int is the integration level. This formula shows the importance of the scale, which should be improved by cameras with higher resolutions or zoom lenses. The verification of the algorithm shows that the positions get less accurate further on in the image sequence, which is confirmed by formula (5). The integration level seems to improve the accuracy, however in reality too high integration levels can result in wrong estimations of the gray values and no improvement is achieved.

In the accuracy budget of the velocity and acceleration it is seen that increasing the framerate has a negative effect on the accuracy and it is advised to improve the resolution first before the framerate is improved.

$$
\begin{aligned}
& \Delta v=\text { framerate } \cdot \frac{\text { scale }+\Delta \text { scale }}{2^{\text {int }}} \\
& \Delta a=2 \cdot \text { framerate }^{2} \cdot \frac{\text { scale }+\Delta \text { scale }}{2^{\text {int }}}
\end{aligned}
$$

Because the difference in position between two images is used to calculate the velocity and acceleration, formula (6) and (7) show no up pilling of errors. The best recording in this study has a scale of $173 \mu \mathrm{m} /$ pixel and an uncertainty of $0.45 \mu \mathrm{m} /$ pixel. For an integration level of 5 this would give the accuracy budgets as given in table 1 . Here it needs to be noted that smoothing methods will improve the accuracy.

\begin{tabular}{|c|c|c|c|}
\hline $\begin{array}{c}\text { Framerate } \\
{[\mathrm{fps}]}\end{array}$ & $\Delta \operatorname{pos}[\mu \mathrm{m}]$ & $\Delta v[\mathrm{~mm} / \mathrm{s}]$ & $\Delta a[\mathrm{G}]$ \\
\hline 8000 & 5.4 & 43 & 71 \\
\hline 16000 & 5.4 & 87 & 283 \\
\hline 32000 & 5.4 & 173 & 1132 \\
\hline
\end{tabular}

Table 1. Accuracy budgets of a recording with a scale of $173 \pm 0.45$ $\mu \mathrm{m}$ and an integration level of 5 .

The accuracy budget of the strain is given in the formula below in which the sub indices 1 and 2 symbolize different pixels:

$\Delta \varepsilon=\left(\frac{\left(\left|u_{1}\right|+\left|u_{2}\right|\right)}{\left|p o s_{2}-p o s_{1}\right|}+\frac{2 n\left(u_{1}-u_{2}\right)}{\left(p o s_{2}-p o s_{2}\right)^{2}}\right) \cdot \frac{\text { scale }+\Delta \text { scale }}{2^{\text {int }}}(8)$

Due to the dependence of $\Delta \varepsilon$ on a lot of parameters it is difficult to give an estimation of the accuracy, but formula (8) leads to the following conclusions:

- When the dots are located close to each other, the error increases.

- When the displacements are high, the error increases.

- The further the sequence gets the more inaccurate the results become.

The first item means that the calculation of local stains is less accurate than the calculation of global strains. Item two means that the error during the free fall is higher than during the impact. For other parameters it is very difficult to give an accuracy budget, but the results should always be interpreted in a careful way.

\section{Results}

The impact of a horizontal orientated phone that is dropped from 2 meter, is recorded at $8000 \mathrm{fps}$ on a scale of $238 \mu \mathrm{m} / \mathrm{pixel}$. A typical image of this recording is shown in figure 2 .

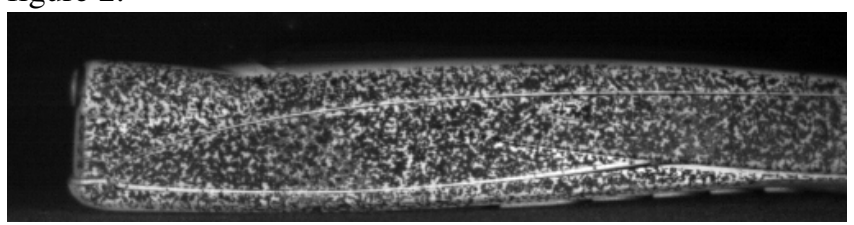

Figure 2: Recording of the impact of a phone dropped from 2 meter.

In this recording a grid over the whole phone and local areas are examined, so the the overall movement of the phone can be analyzed and a comparison between different local areas on the phone can be made. For the overall movement of the phone a rectangular grid over the speckle is taken, but because the side of the phone is built up out of the main body and two covers, the grid has to be kept small 
in order to have points only on the main body. The displacements of the local areas are calculated by taking the average of $6 \times 6$ pixels that are next to each other.

The movement of the whole phone can be visualized in dotplots of the overall grid, in which the positions of the different dots in the different images are plotted. The positions of the dots with respect to each other give insight of the orientation and deformation of the phone.

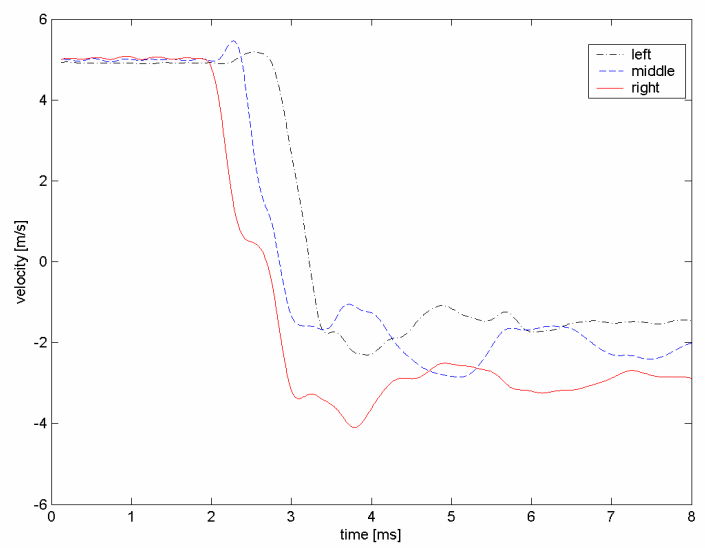

Figure 3: The average vertical velocity of 25 pixels on the left, middle and right of the main body of a horizontal orientated phone dropped from 2 meter.

The vertical speed of every local area is plotted in figure 3 . The lines show that the right side hits the ground first followed by the middle and the left. This results in a small rotational movement, which gives a small peak in velocity for two areas. This rotation can also be seen in the image sequence of the phone and in the dotplots.

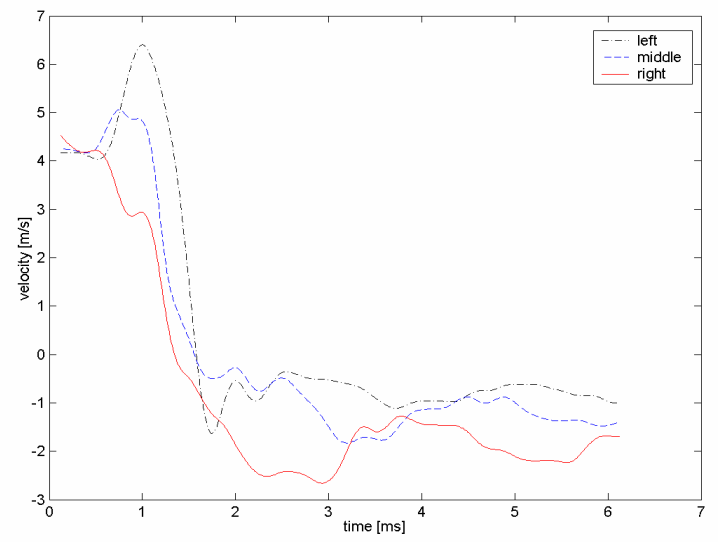

Figure 4: The average velocity of 25 pixels on the left, middle and right of the main body of a horizontal orientated phone dropped from 1.5 meter.

The velocity profiles of the same three areas on a phone dropped from 1.5 meter are plotted in figure 4. During this drop the phone is more rotated when it hits the grounds and higher peaks in velocity are measured.

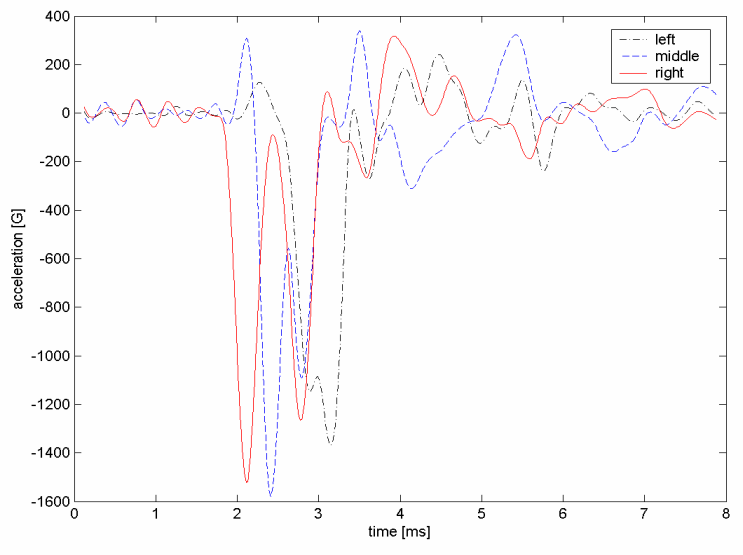

Figure 5: The average acceleration of 25 pixels on the left, middle and right of the main body of a horizontal orientated phone dropped from 2 meter.

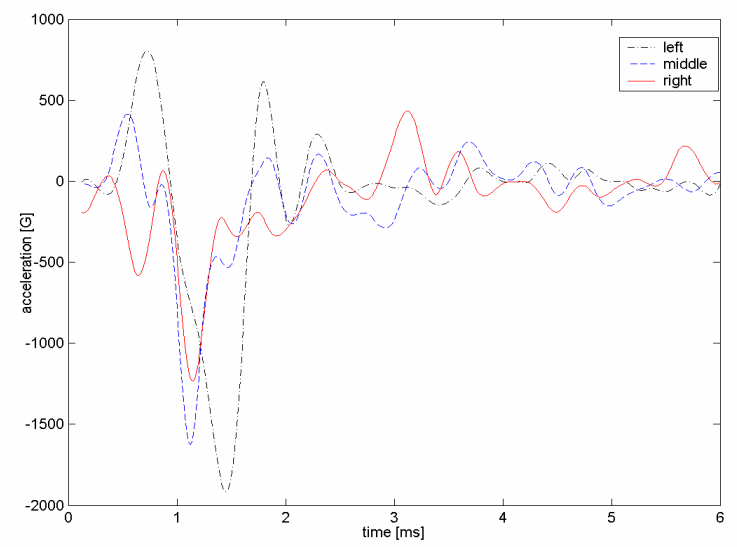

Figure 6: The average acceleration of 25 pixels on the left, middle and right of the main body of a horizontal orientated phone dropped from 1.5 meter.

These changes in velocity results in acceleration peaks, which are plotted for the 2 and 1.5 meter drop in figure 5 and figure 6, respectively. Figure 6 shows that the accelerations at different positions on the phone can vary in a great degree, which shows the need to examine the impact at different points on a phone. Figure 6 shows higher accelerations than figure 5, because the phone dropped from 1.5 meter has a bigger rotation at the moment of impact. The highest acceleration for the left, middle and right area in the drop from 2 meter is, respectively, 1400, 1600 and $1500 \mathrm{G}$. For the 1.5 meter drop these accelerations are 1200, 1600 and $1900 \mathrm{G}$ respectively.

According to the JEDEC standard [7] the impact time is the width of a half sinus shaped acceleration peak. For acceleration peaks in figures 5 and 6 , it is difficult to determine the width of one peak, because different peaks interfere with each other. To give a rough estimation of the impact time the peaks need to be extrapolated, which gives estimations for impact times of the left, middle and right area of the phone drop from 2 meter of $0.64,0.54$ and 0.57 $\mathrm{ms}$, respectively. For the phone drop from 1.5 meter the impact times of the left, middle and right area are $0.49,0.48$ and $0.47 \mathrm{~ms}$, respectively. 
Out of the average velocity profile of the grid over the main body, the velocity before and after impact is estimated. Out of the difference in these velocities, the energy loss of the phone can be estimated.

$U_{\text {loss }}=\frac{1}{2} m\left(v_{\text {impact }}^{2}-v_{\text {rebound }}^{2}\right)$

By using formula (9) it is calculated that phone dropped from 2 meter loses $84 \%$ of its original energy equivalent to 1.26 Joule and the phone dropped from 1.5 meter loses $90 \%$ equivalent to 0.93 Joule.

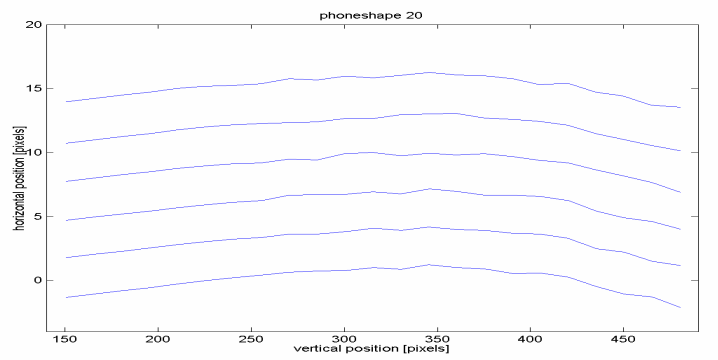

Figure 7: Magnified bending profile of the grid on the phone dropped from 2 meter, $0.125 \mathrm{~ms}$ after impact.

The bending of the phone is visualized in figure 7 for the second image after impact of the phone dropped from 2 meter. The scale of the vertical axis is not the same as the scale of the horizontal axis, so the bending is magnified. The further the sequence gets, the less smooth the lines become, which illustrates the loss in accuracy at high image numbers as is seen in formula (5).

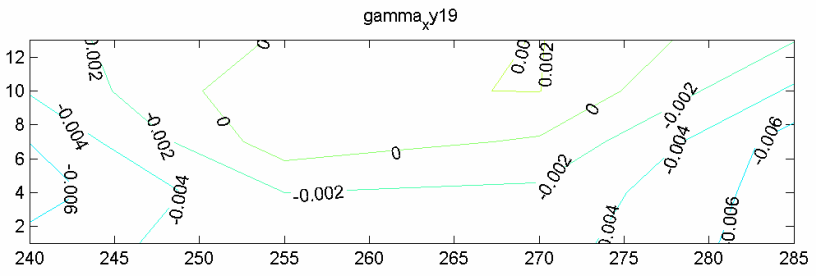

Figure 8: $\varepsilon_{\mathrm{x}}$ in a part of a horizontal dropped phone from 2 meter at the moment of impact.

In an effort to examine the strains the grid over the main body of the phone dropped from 2 meter is examined on the part that bends most in the bending plots, which is an area of $10 \times 3 \mathrm{~mm}$, located about $2.5 \mathrm{~cm}$ from the bottom of the phone. The vertical stain field of this area is given in figure 8. The maximum strain during the whole sequence is 0.06 , but the majority of the strains is smaller than 0.01 .

A vertical drop from 1.5 meter recorded at $16000 \mathrm{fps}$ on a scale of $219 \mu \mathrm{m} /$ pixel shows a different behavior from the horizontal drops. The recording shows that the phone hits the ground first with the corner on the front side and after that with the corner of the backside. This causes accelerations in both $\mathrm{x}$ and $\mathrm{y}$ direction, so the movement of the phone needs to be examined in both directions. This is done for two areas of $6 \times 6$ pixels at the bottom and the middle of the phone.

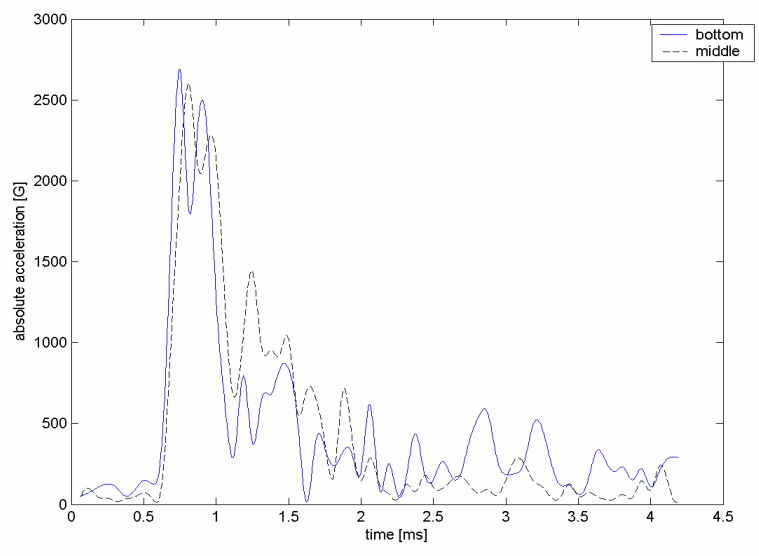

Figure 9: absolute acceleration of the main body of a phone dropped in vertical orientation from 1.5 meter.

The absolute accelerations of those two areas are plotted in figure 9. The highest acceleration peaks in the middle and the bottom area are $2600 \mathrm{G}$ and $2700 \mathrm{G}$, respectively, what is quite higher than the acceleration peaks in the horizontal impact orientation. This shows the need to examine different impact orientations. The impact times are $0.42 \mathrm{~ms}$ for the middle area and $0.36 \mathrm{~ms}$ for the bottom area.

An analysis of the bending shows again that also for the vertical drop most bending takes again place at $2.5 \mathrm{~cm}$ from the bottom. The energy loss is $88 \%$ equivelant to 0.96 Joule. The strains show again an irregular pattern and the highest strain measured is 0.08 . The average of the strains is also higher than those in the horizontal drop, so it can be concluded that the measured accelerations and strains are much higher in a vertical impact orientation than those in a horizontal impact orientation.

\section{Conclusions}

The results of this study shows a promising indication of what is possible with digital image correlation for analyzing portable products during drop impact tests. The big advantage of this method is that it can analyze every arbitrary point on the phone and is not limited to local measurements. Another big advantage is that the measurement system is non contact and can analyze guided free drops, which are realistic and allow the study of different impact positions. The recordings can be used to zoom in on different parts of the phone and compare the velocity, acceleration or strains profiles. The recordings can also be utilized to analyze the overall movement of the phone. In addition new parameters, such as velocity, rotation and bending can be examined. The recording itself is very useful to interpret the results and indicate weak zones in the product.

To keep this method accurate a high speed camera having both a high resolution and framerate is needed. The used drop tester provides good drops, nevertheless the impact orientation can vary, which in turn influences the results. The disadvantage of free drops is that the angle of the recorded plane with the phone can change, which in turn 
changes the recorded speckle. The light conditions needs to be stable at all times during a drop test.

The digital image correlation method shows good results, however it is difficult to give an indication of the overall accuracy of those results. The accuracy of the other results strongly depends on the accuracy of the digital image correlation algorithm and the used equipment. The results of the post calculations provide a good basis for the evaluation of finite element simulations, as well as input for finite element simulations and new design rules.

The conducted tests give extensive insight in the phenomena that take place during drop impact. Many different parameters are obtained, which can be combined to make the right conclusions. Results as dotplots, rotations and bending increase the knowledge of the impact behavior and the recording itself are considerably valuable to examine the movements of the phone.

Two impact orientations have been examined: a horizontal drop and a vertical drop. The comparison of different places on the phone during a horizontal drop shows that the impact parameters at different positions can vary from $1200 \mathrm{G}$ to $1900 \mathrm{G}$. Accelerations in a vertical drop from 1.5 meter can be as high as $2700 \mathrm{G}$, which is higher than accelerations in a horizontal drop. Conclusions on strains are difficult to obtain, because of the irregular strain patterns, but they can be quite high. The visualization of bending shows where the phone bends most. Although impact times are difficult to calculate, due to the interference of different acceleration peaks, rough estimations can be given. The combination of all the results obtained in the undertaken study provide an extensive insight in the impact behavior of a mobile phone.

\section{Acknowledgments}

The authors gratefully acknowledge Prof. Xiaoyuan He from the Southeast University for technical support.

\section{References}

1. Tee, T.Y. and Ng, H.S. and Lim, C.T., Pek E. And Zhong, Z.W. Impact life prediction modeling of TFBGA packages under board level drop test, Microelectronics reliability journal. 2004; 44: 1131-1142.

2. Tee, T.Y. and Ng, H.S. and Lim, C.T., Pek E. and Zhong, Z.W. Board level drop test and simulation of TFBGA packages for telecomunication applications, 53rd ECTC Conference. New Orleans, Louisana USA, May 2003: 121-129.

3. Kim, J.G. and Park, Y.K.. Experimental verification of drop/impact simulation for a cellular phone. Society for experimental mechanics. August 2004; 44 (4): 375-380.

4. Ong, Y.C. and Shim, V.P.W. and Chai, T.C. and Lim, C.T. Comparison of Mechanical Response of PCBs Subjected to Product-Level and Board-Level Drop Impact Tests, EPTC Conference Proceeding, Singapore. December 2004.

5. Shi, D.X.Q. and Pang, H.L.J. and Zhang, X.R. and Liu, Q.J. and Ying, M. In-Situ Micro-Digital Image Speckle
Correlation Technique for Characterization of Materials' Properties and Verification of Numerical Models, IEEE transactions on components and packaging technologies. 2004; 27(4): 659-667.

6. Pang, H.L.J. and Shi, D.X.Q. and Zhang, X.R. and Liu, Q.J. Application of Digital Speckle Correlation to Micro-deformation Measurement of a flip chip assembly, 53rd Electronic components and technology conference. New Orleans, LA, USA. 2003: 926-932.

7. JESD22-B111, Board level drop test method of components for handheld electronic products. JEDEC Solid State Technology Association, Arlington, July 2003.

\section{Biography}

P.L.W. Scheijgrond is a MSc student at the Department of Mechanical Engineering of the Eindhoven University of Technology, Eindhoven, the Netherlands. This work has been done during a traineeship at Philips Mobile Display Systems, Shanghai, China.

D.X.Q. Shi is appointed at Philips Electronics Components (Shanghai) Co. Ltd.. He has published more than 70 international journal and conference papers. His main research interests include microsystems packaging, advanced electronics materials, micro- and nanomeasurement techniques and finite element modelling..

W.D. van Driel is appointed at Philips Semiconductors, IMO-Backend Innovation Organization, The Netherlands. His areas of interest are virtual prototyping and virtual reliability qualification of microelectronics, and designing for thermo-mechanical reliability of electronic packages and systems.

G.Q. Zhang is appointed at the CTO of Philips Semiconductors, and part-time professor at the Delft University of Technology, the Netherlands. He is author and co-author for more than 100 scientific publications, including journal and conference papers, book and invited keynote lectures. His scientific interests include virtual prototyping and virtual qualification, development of fundamental and application knowledge of computational \& experimental mechanics, advanced optimization methods, and especially their applications in microelectronics and microsystems.

H. Nijmeijer obtained his MSc-degree and $\mathrm{PhD}$-degree in Mathematics from the University of Groningen, Groningen, the Netherlands, in 1979 and 1983, respectively. From 1983 untill 2000 he was affiliated with the Department of Applied Mathematics of the University of Twente, Enschede, the Netherlands. Since 2000, he chairs the Dynamics and Control section of the Department of Mechanical Engineering of the Eindhoven University of Technology. Henk Nijmeijer is (associate) editor of various journals in dynamics and control. He is a fellow of the IEEE and was awarded in 1987 the IEE Heaviside premium. 